\title{
Article \\ Integrating Optical and Wireless Techniques towards Novel Fronthaul and Access Architectures in a 5G NR Framework
}

\author{
Ramon Maia Borges ${ }^{1,2}{ }^{(D}$, Celso Henrique de Souza Lopes ${ }^{1}$, Eduardo Saia Lima ${ }^{1}$, Marco Aurélio de Oliveira ${ }^{1}$, \\ Matheus Sêda Borsato Cunha ${ }^{1,2}$, Luciano Camilo Alexandre ${ }^{1}$ D, Luis Gustavo da Silva ${ }^{1}$, \\ Luiz Augusto Melo Pereira ${ }^{1}$, Danilo Henrique Spadoti ${ }^{2}$, Murilo Araujo Romero ${ }^{3}$ and \\ Arismar Cerqueira Sodré Junior $1, *$ (D)
}

1 Laboratory WOCA, National Institute of Telecommunications (Inatel), Santa Rita do Sapucaí 37540-000, MG, Brazil; ramonmb@inatel.br (R.M.B.); celso.lopes@mtel.inatel.br (C.H.d.S.L.); elima@get.inatel.br (E.S.L.); marcoaurelio@mtel.inatel.br (M.A.d.O.); matheusseda@gee.inatel.br (M.S.B.C.); luciano.camilo@mtel.inatel.br (L.C.A.); luis.gustavo@inatel.br (L.G.d.S.); luiz_augusto@get.inatel.br (L.A.M.P.)

2 Department of Electrical Engineering, Federal University of Itajubá (UNIFEI), Itajubá 37500-903, MG, Brazil; spadoti@unifei.edu.br

3 Department of Electrical and Computer Engineering, University of São Paulo (USP), EESC/USP, São Carlos 13566-590, SP, Brazil; murilo.romero@usp.br

* Correspondence: arismar@inatel.br; Tel.: +55-35-3471-9200

\section{check for}

updates

Citation: Borges, R.M.; de Souza Lopes, C.H.; Lima, E.S.; de Oliveira, M.A.; Cunha, M.S.B.; Alexandre, L.C.; da Silva, L.G.; Pereira, L.A.M.; Spadoti, D.H.; Romero, M.A.; et al. Integrating Optical and Wireless Techniques towards Novel Fronthaul and Access Architectures in a 5G NR Framework. Appl. Sci. 2021, 11, 5048. https://doi.org/10.3390/app11115048

Academic Editor: Fabio Cavaliere

Received: 1 May 2021

Accepted: 24 May 2021

Published: 29 May 2021

Publisher's Note: MDPI stays neutral with regard to jurisdictional claims in published maps and institutional affiliations.

Copyright: (c) 2021 by the authors. Licensee MDPI, Basel, Switzerland. This article is an open access article distributed under the terms and conditions of the Creative Commons Attribution (CC BY) license (https:/ / creativecommons.org/licenses/by/ $4.0 /)$.
Abstract: The fifth-generation of mobile network (5G) and beyond requires a radio access network (RAN) update in order to cope with the incoming increase of wireless data traffic and new applications. In this context, we propose an efficient optical-wireless architecture applied to the non-standalone (NSA) 5G new radio (NR) framework. Several distinct electrical- and optical-based fronthaul configurations combining free-space optical (FSO), wireless links, and radio over fiber (RoF) techniques were implemented and properly analyzed for selection according to network operator deployment requirements. In addition, visible light communication (VLC) was investigated as a future access network technology when immunity to electromagnetic interference is paramount. Experimental results demonstrated fourth-generation of mobile network (4G) and 5G coexistence at Gbit/s throughput and error vector magnitude (EVM) in accordance with 5G NR Release 15.

Keywords: 4G/5G; fronthaul; optical-wireless systems; VLC

\section{Introduction}

The fifth-generation of mobile network (5G) has already started to be commercially implemented around the world. At this initial implementation stage, 5G typically operates in the non-standalone (NSA) mode, aiming to take advantage of the fourth-generation (4G) infrastructure to deploy $5 \mathrm{G}$ new radio (5G NR) systems. Therefore, $5 \mathrm{G}$ and $4 \mathrm{G}$ share the network infrastructure and must coexist seamlessly [1]. Phase 1 of $5 \mathrm{G}$ systems is based on the 3rd Generation Partnership Project (3GPP) Release 15, which defines the 5G NR standard by focusing on the enhanced mobile broadband (eMBB) scenario. Technical solutions explored at this stage include radio equipment design, use of additional spectral bands encompassing millimeter-waves (mm-waves), flexible resource allocation, and multiple input multiple output (MIMO) schemes [2,3]. In addition, 5G deployment requires a radio access network (RAN) update in order to cope with the planned increase in wireless data traffic. Trends in network planning point to optical-wireless convergence, mobile dense heterogeneous networks (HetNet), centralized RAN (C-RAN), and the so-called "Xhaul", which integrates backhaul (BH), midhaul (MH), and fronthaul (FH) transport networks [4-6].

Recently, 3GPP completed Release 16 for phase 2 of 5G systems, which considers ultrareliable low latency communication (URLLC) and massive machine-type communication 
(mMTC) applications. According to the release, the technical solutions to be explored include integrated access and backhaul (IAB), industrial Internet of Things (IoT), satellite access, and NR-based access to unlicensed spectrum [7]. Releases 17 and 18 for 5G are currently in production and scheduled to end in 2021, with the goal of further enhancing mobile systems [8]. By the same token, planning of sixth-generation (6G) communications has already begun, focused on providing performance superior to $5 \mathrm{G}$ and satisfying future demands as far as 2030. Among the potential technologies for 6G, optical-wireless convergence continues to play an important role for future RANs, whereas terahertz and visible light communications (VLC) have also emerged $[9,10]$.

In this context, a key area of study is microwave photonics (MWP), which takes advantage of optical and mobile communications for signal distribution in a heterogeneous architecture [11,12]. MWP techniques have been strongly applied to radiofrequency (RF) generation, processing, detection, transport, and distribution. Notably, radio over fiber (RoF) technology enables transportation and distribution of digital and/or analog signals among central office (CO) and remote radio units (RRUs) via fiber-optic links, giving rise to the fiber-wireless (FiWi) systems [11,13]. From a C-RAN point of view, HetNet in conjunction with picocell and femtocell implementations allows system coverage and data rate to be enhanced. In C-RAN architecture, the backhaul and fronthaul links connect CO to the core network, typically carrying digital user data and CO to RRUs, respectively.

Fifth-generation systems are mostly based on digital radio over fiber (D-RoF) using the common radio public interface (CPRI) protocol, in which radio signals are sampled and directly digitalized into baseband data at the remote radio head (RRH) from the cell site. Millimeter-wave operation requires high-speed A/D (analog-to-digital) and D/A (digital-to-analog) converters, creating a bandwidth bottleneck in uncompressed CPRI. To address this issue, two main network alternatives have been actively investigated. One possibility is functional split (FS), widespread by 3GPP under e-CPRI. The FS establishes that some network functionalities be carried out at RRHs, thereby alleviating the transmission rate requirements for the $5 \mathrm{G}$ fronthaul. Specifically, 3GPP has defined a series of options for functional split between BBU and RRHs. In short, functional splits decentralize control functionalities in such way as to establish a trade-off between reducing fronthaul throughput and increasing latency. The other option is analog fronthaul (A-RoF), in which the RF wireless signal modulates an optical carrier that is optically distributed. Because there is no high-speed A/D conversion, the system is far less complex and the overall latency is much smaller, dictated essentially by the optical fiber length.

Our research group has been intensely investigating A-RoF solutions for multiband and Gbit/s 5G systems in recent years [14-17]. The solution presented in [14] takes advantage of an operating gigabit passive optical network (GPON) from a local Internet service provider to distribute 5G-like signals, thus making use of an existing network infrastructure for $5 \mathrm{G}$ fronthaul in accordance with C-RAN. The approaches presented in $[15,16]$ explore optical link not only for data transmission but also as a medium to perform photonics-assisted RF amplification. In [17], a dual-band wireless fronthaul using an FSS-based focal point/Cassegrain antenna assisted by an optical midhaul was demonstrated.

Alternatively, free-space optical (FSO) technology has also shown potential for 5G transport network deployment using the unlicensed terahertz bands [18,19]. For instance, Mufutau et al. successfully reported a hybrid RoF/FSO fronthaul approach in which 5G coexists with $4 \mathrm{G}$ by means of coarse wavelength division multiplexing (CWDM) [19]. These previous works considered wireless links operating at a variety of radiofrequencies for providing mobile access, which might be either indoor or outdoor. Overall, RF links correspond to the main technical solution employed for access, although visible light communications (VLC) have also been recognized as an alternative for indoor environments, particularly when RF electromagnetic interference must be avoided [20,21].

Apart from a tiny segment of the worldwide market already using VLC, wireless access networks are almost entirely based on electrical solutions, with approximately $70 \%$ 
of macrosites in the world being connected by microwave fronthauls. Although there are many published works investigating individual proposals regarding fronthaul solutions, only a few of them present comparisons between different optical-based fronthaul solutions [22,23]. To the best of our knowledge, work addressing and confronting diverse electrical- and optical-based fronthauls is still missing in the specialized literature.

In this context, the current study relies on integrating optical and wireless techniques towards novel fronthaul and access architectures in a NSA 5G NR framework, as proposed in Figure 1. In other words, we report implementations and comparison of diverse MWP techniques towards a non-standalone 5G NR optical-wireless communications (OWC) architecture in such a way that a variety of integrated services may be offered according to the network operator needs.

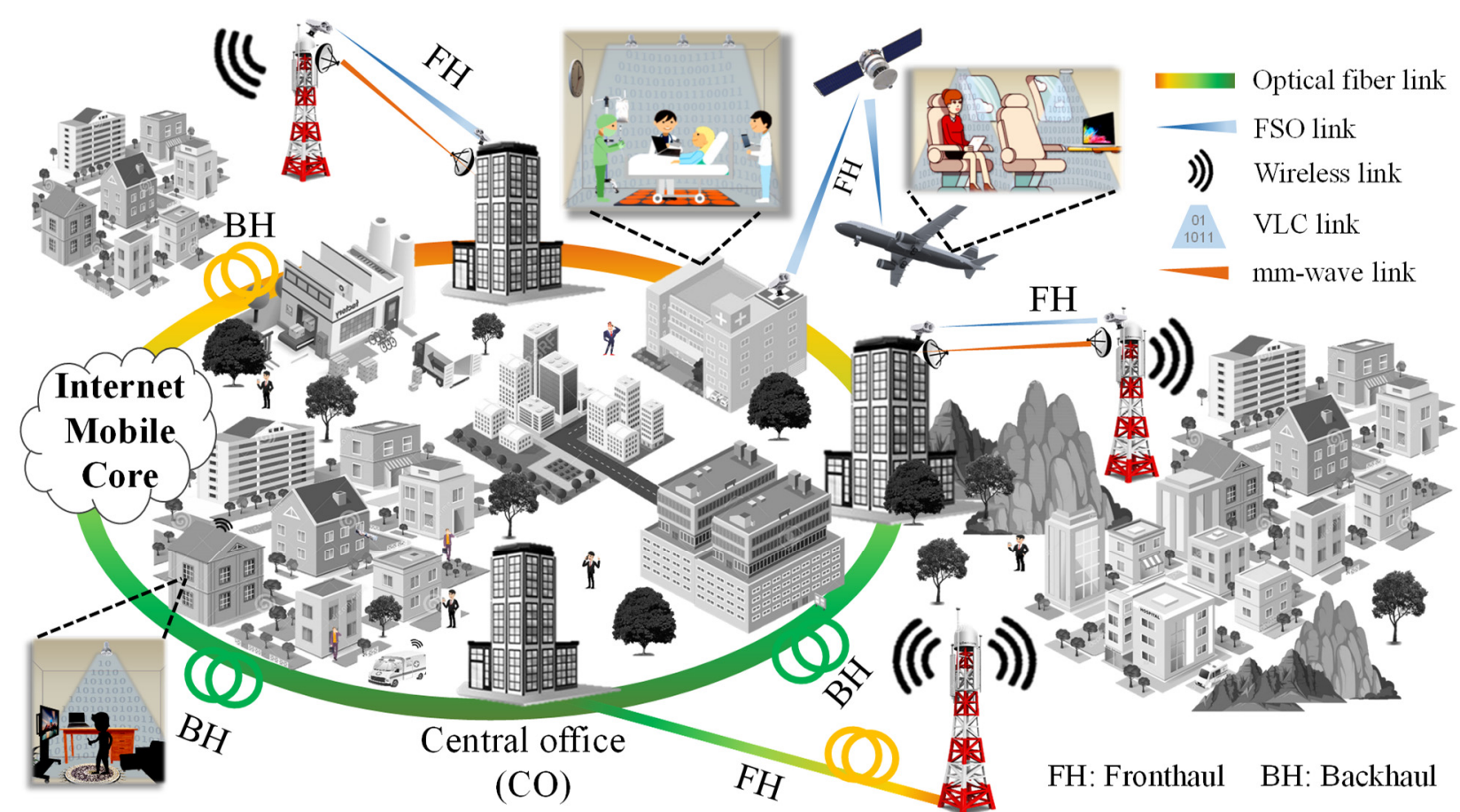

Figure 1. Optical-wireless communication system based on RoF/FSO/wireless fronthaul configurations combined to VLC/wireless access for $5 \mathrm{G}$ and beyond.

The main contributions of this study are as follows: proposal and implementation of optical-wireless architectures applied to the NSA 5G NR framework; evaluation of diverse transport and access network solutions, including 5G NR dual wireless and FSO-based fronthaul, 4G/5G NR fiber-wireless fronthaul, combined fiber-optic and FSO-based 5G fronthaul, and $4 \mathrm{G} / 5 \mathrm{G}$ NR VLC-based access network; discussion of experimental results regarding $4 \mathrm{G}$ and $5 \mathrm{G}$ coexistence at Gbit/s throughput and error vector magnitude (EVM) in accordance with 3GPP Release 15.

The focus of our work is data transmission in the physical layer, although Figure 1 provides a unifying view of our applications in a single ecosystem. The rest of the paper is structured as follows. In Section 2, we address different fronthaul configurations. First, in Section 2.1, a dual wireless and FSO-based fronthaul that enables a backup link for highreliability services is reported. In Section 2.2, a RoF-based fronthaul is demonstrated for simultaneous RF signal distribution at distinct spectral bands. Unlike previous works [7,8], a single wavelength is used to simultaneously cover $4 \mathrm{G}$ and 5G NR applications, including millimeter-wave bands. Next, in Section 2.3, we discuss a RoF/FSO-based fronthaul that enables high-capacity fronthaul extension for regions where optical fibers cannot be deployed all the way. A VLC-based access network for indoor applications is presented 
in Section 3, targeting applications in which immunity to electromagnetic interference is crucial. Section 4 compares the obtained results to related works from the literature. Conclusions, final remarks, and future works are outlined in Section 5.

\section{Fronthaul Solutions for $4 \mathrm{G} / 5 \mathrm{G}$}

This section reports on the architectures and experimental results for the three fronthaul configurations illustrated in Figure 1, namely 5G NR dual wireless and FSO-based fronthaul, 4G/5G NR FiWi-based fronthaul, and combined fiber-optic and FSO-based 5G fronthaul.

\subsection{The 5G NR Dual Wireless and FSO-Based Fronthaul}

Figure 2a depicts a block diagram of the dual wireless and FSO-based fronthaul architecture, in which the two parallel data transmission paths enable link dynamic selection according to transmission performance at a given instant, while the other link serves as a backup. The FSO and RF links were implemented at $1550 \mathrm{~nm}$ and $38 \mathrm{GHz}$, respectively. The hybrid FSO/RF system was analyzed under the 5G NR standard operating with $400 \mathrm{MHz}$ bandwidth and $120 \mathrm{kHz}$ between orthogonal frequency division multiplexing (OFDM) subcarriers for quadrature phase shift keying (QPSK) and 16- and 64-quadrature amplitude modulation (QAM).

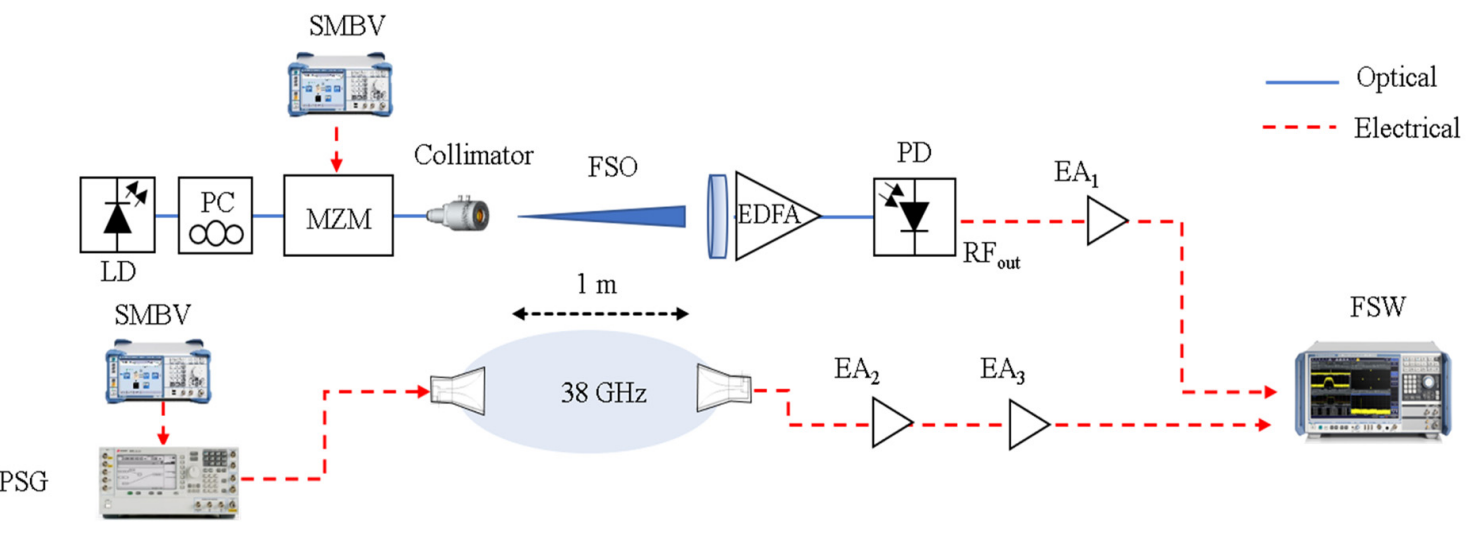

(a)

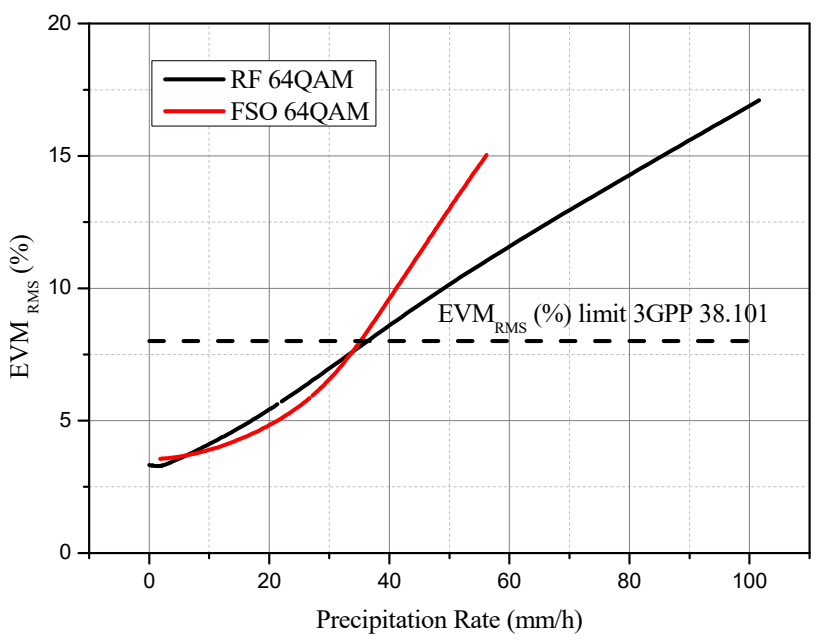

(b)

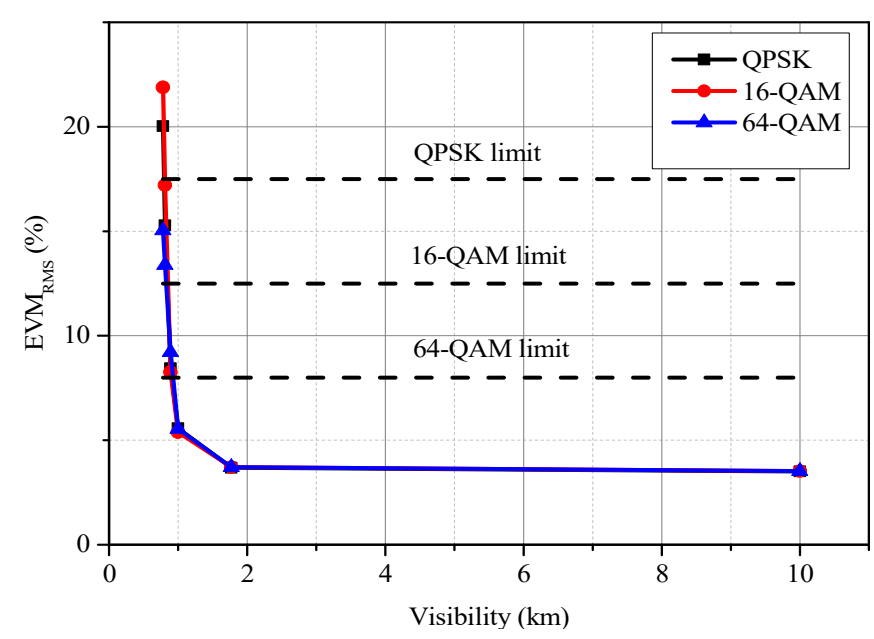

(c)

Figure 2. The 5G NR dual wireless and FSO-based fronthaul. (a) Block diagram of the proposed hybrid wireless-FSO system. From the left, the signal generated by the vector signal generator (VSG) SMVB100A reaches the FSW signal and spectrum analyzer via the two different links. (b) Dependence of hybrid FSO/RF EVMRMS as a function of rain precipitation rate.

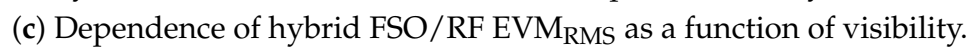


In the experiments, a SMVB100A vector signal generator (VSG) was responsible for generating 5G NR signal at $1 \mathrm{GHz}$ with $400 \mathrm{MHz}$ bandwidth for the QPSK, 16-QAM, and 64-QAM schemes. In the FSO link, the modulated RF signal was inserted into a single-drive Mach-Zehnder modulator (MZM) based at the quadrature point. A distributed feedback (DFB) laser at $1550 \mathrm{~nm}$ provided the optical carrier, which fed the MZM after passing through a polarization controller (PC). The MZM output was coupled to a collimator to prepare the optical beam for transmission in free space. The transmitted optical beam was then captured by a M-5X objective lens and coupled to a single-mode fiber (SMF). The received signal was amplified by an Erbium-doped fiber amplifier (EDFA) and then photodetected by a $p$-intrinsic- $n$ (PIN) broadband photodetector $\left(\mathrm{u}^{2} \mathrm{t}\right.$ XPDV2120RA). Before demodulation in the electrical spectrum analyzer (FSW), the RF signal was amplified by a low-noise amplifier (LNA, EA 1 ). As in references [24] and [25], an FSO link of a few meters was taken as a proof-of-concept for $5 \mathrm{G}$ networks to assure an eye-safe indoor environment. As shown below, real-life performance was emulated by varying the optical power reaching the optical receiver.

Meanwhile, for the RF link, the same 5G NR signal, once again generated by a SMVB100A VSG, was used to drive the PSG E8267D equipment, which upconverted the 5G NR frequency to $38 \mathrm{GHz}$. Posterior, its output was connected to a $25 \mathrm{dBi}$ horn antenna, and an identical antenna was used at the receiver side with the same height and polarization. A two-stage amplification $\left(\mathrm{EA}_{2}\right.$ and $\left.\mathrm{EA}_{3}\right)$ scheme was employed before demodulation.

The performance of the hybrid FSO/RF is presented in Figure $2 b, c$ through $E_{\text {VVMS }}$ measurements at different power levels at the receiver, emulating equivalent attenuation levels according to visibility and rain conditions. These power levels at the receiver ranged from -41.9 to $-7.4 \mathrm{dBm}$. Regarding the effect of rain attenuation, the attenuation levels used for the FSO link ranged from 0 to $56 \mathrm{~mm} / \mathrm{h}$, while the values ranged from 0 to $102 \mathrm{~mm} / \mathrm{h}$ for the wireless link. For the specific case of 64-QAM, the 3GPP EVM RMS limit was reached at about the same precipitation intensity for both FSO and $38 \mathrm{GHz}$ wireless links ( $36 \mathrm{~mm} / \mathrm{h}$, Figure $2 \mathrm{~b}$ ). However, as shown in Figure $2 b$, while operating in a rainy environment, the wireless link suffered less significant performance degradation as the rain intensity increased.

Figure 2c depicts the dependance of EVM regarding visibility for the FSO link for three distinct modulation formats. In every case, successful transmission within the 3GPP standards required a visibility above $780 \mathrm{~m}$. In contrast, the visibility issue was much less severe for the wireless link. In fact, our experimental results demonstrated a $1.61 \mathrm{Gbps}$ 64-QAM throughput, which is within the 3GPP EVM requirements, as long as the rain intensity was less than $36.4 \mathrm{~mm} / \mathrm{h}$ (see Figure 2a) and the visibility exceeded $40 \mathrm{~m}$.

\section{2. $4 G / 5 G$ NR Fiber-Wireless (FiWi) Fronthaul}

The long-term evolution-advanced (LTE-A) and 5G NR signals have similar physical channel configurations, including primary (P-SS) and secondary synchronization signal (S-SS), physical transmission channel (PBCH), demodulation reference (DMRS), and shared physical data channel (PDSCH). Different modulation formats are used for the data and control channels. For instance, data signals might be modulated in 64-QAM format, while binary phase shift keying (BPSK) modulation is applied for modulating the P-SS and S-SS channels. In addition, QPSK and 64-QAM are utilized for PBCH-DMRS and PDSCH signals, respectively [19].

The EVM $\mathrm{RMS}_{\text {R }}$ performance of the FiWi system was investigated for the eRAC scenario operating in the $700 \mathrm{MHz}$ frequency range. Figure 3a displays a block diagram of the experimental arrangement of the proposed FiWi system, which employs an A-RoF configuration based on external modulation and direct detection followed by a link access for increased reach. 


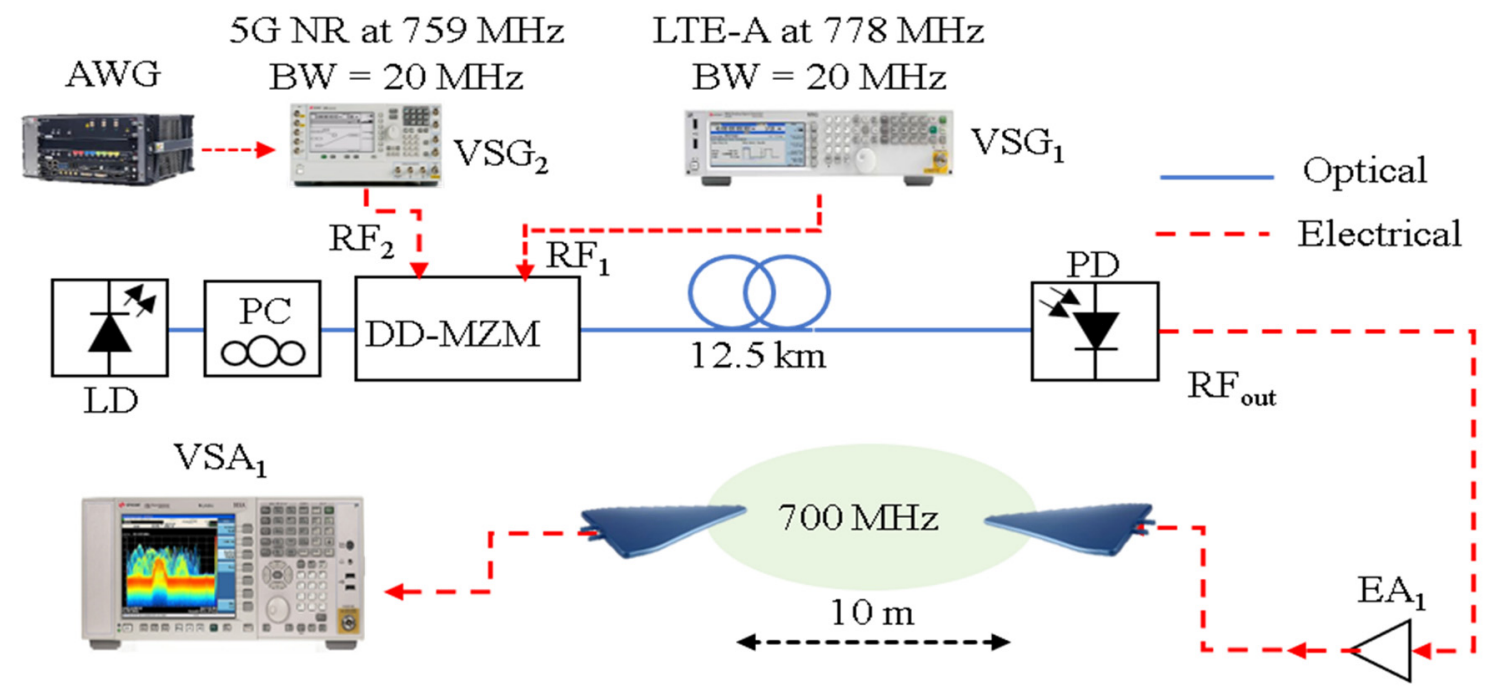

(a)
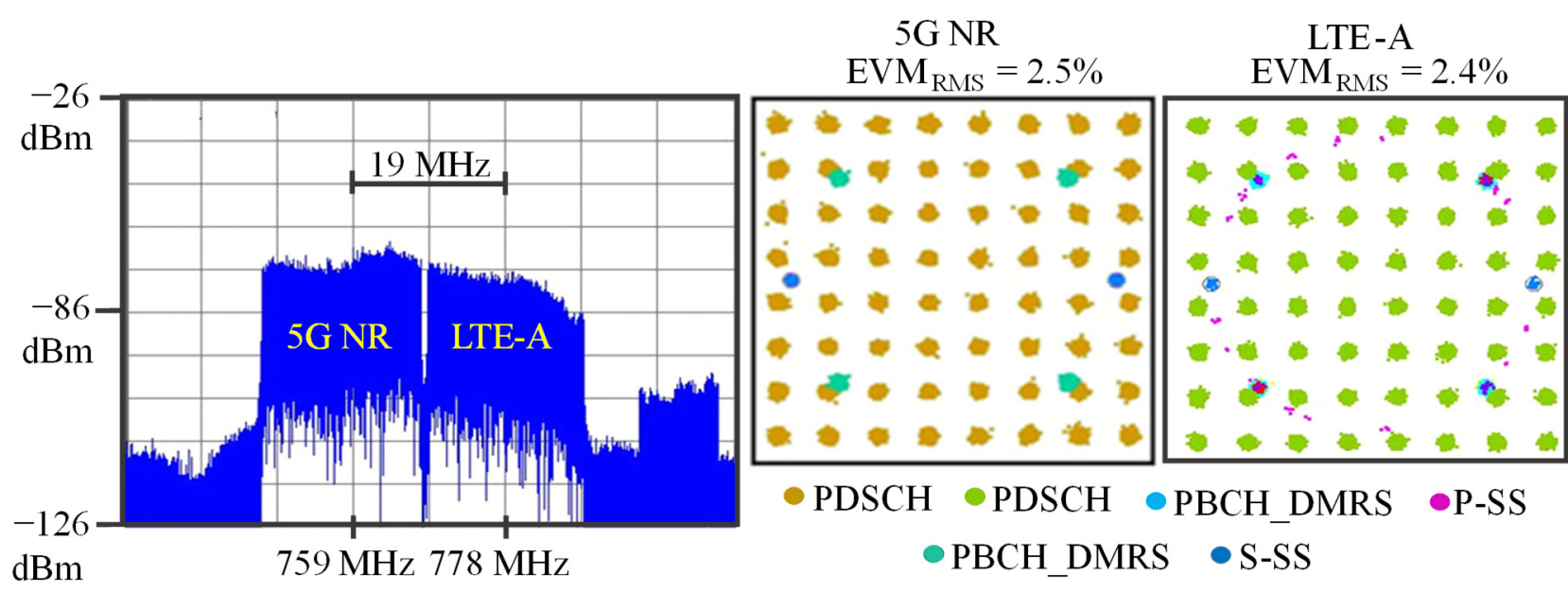

(b)

Figure 3. The 4G/5G NR fiber-optic-based fronthaul architecture. (a) Block diagram; (b) coexistence analysis between 4G and $5 \mathrm{G}$ technologies in the optical-wireless system.

An EXG generator (N5171B) from Keysight generated the LTE-A signal $\left(\mathrm{VSG}_{2}\right)$ at $778 \mathrm{MHz}$, which was configured offline using the Keysight Signal Studio software for generating signals with $20 \mathrm{MHz}$ bandwidth and 64-QAM. The $20 \mathrm{MHz}$ baseband 5G NR signal was also configured by means of the Signal Studio software in conjunction with an arbitrary waveform generator (AWG M9505A). Next, the PSG E8267D converted the baseband 5G NR signal to the $759 \mathrm{MHz}$ band $\left(\mathrm{VSG}_{1}\right)$. This approach allowed the transmission of the LTE-A and 5G NR signals coexisting in adjacent channels, thereby making use of the non-standalone transmission mode proposed by 3GPP in Release 15 [3].

A dual-drive Mach-Zehnder modulator (DD-MZM) modulated an optical carrier provided by a laser at $1560 \mathrm{~nm}$ with two distinct RF signals. The optical beam was then launched into a single-mode fiber with $0 \mathrm{dBm}$ of optical power. Nonlinearities were not observed in our approach as the optical power level in the SMF did not reach the power thresholds leading to nonlinear effects [26]. Regarding the electrical power levels, $\mathrm{RF}_{1}$ and $\mathrm{RF}_{2}$ signals were transmitted at $-5 \mathrm{dBm}$, while the PIN photodetector (EOT ET-5000F) received a fixed optical power of $-3 \mathrm{dBm}$. After photodetection, the signals in the electrical domain were amplified by about $44 \mathrm{~dB}\left(\mathrm{EA}_{1}\right)$ to compensate for the overall system losses. Two log-periodic broadband antennas with $5 \mathrm{dBi}$ gain were used to transmit and receive 
both $\mathrm{RF}_{1}$ and $\mathrm{RF}_{2}$, and a $10 \mathrm{~m}$ wireless transmission was performed as a proof-of-concept. At the receiver side, a Keysight MXA N9020A vector signal analyzer (VSA 1 ) was used to demodulate the received signals and provide the $\mathrm{EVM}_{\mathrm{RMS}}$ measurement results.

In the experiments, a $19 \mathrm{MHz}$ frequency offset was employed between $\mathrm{RF}_{1}$ and $\mathrm{RF}_{2}$. This offset was determined as a preliminary step in order to find the minimum frequency offset allowing seamless coexistence between the $R_{1}$ and $R_{2}$ signals. Specifically, we measured the EVM $\mathrm{RMS}_{\mathrm{S}}$ as a function of the central frequency offset between the LTE-A and 5G NR signals. The LTE-A central frequency was kept at $778 \mathrm{MHz}$ central frequency, whereas the 5G NR central frequency was varied from 760 to $758 \mathrm{MHz}$. For a $18 \mathrm{MHz}$ frequency offset, there was a spectral overlap of $2 \mathrm{MHz}$ between the signals, resulting in EVM $_{\text {RMS }}$ higher than 19\%. This exceeds the limits specified by 3GPP [27], making the system unsuitable for 64-QAM transmission. In contrast, the $19 \mathrm{MHz}$ offset was enough to assure an $\mathrm{EVM}_{\mathrm{RMS}}$ value below 3\%. For this offset, there was still a spectral overlap of 1 $\mathrm{MHz}$ between the signals. However, this overlap occurred in the lateral lobes and did not significantly affect the quality of the received signal after the optical fronthaul.

Having established an offset of $19 \mathrm{MHz}$, the optical-wireless system based on nonstandalone mode was implemented using a RF power level of $-5 \mathrm{dBm}$ for the $\mathrm{RF}_{1}$ and $\mathrm{RF}_{2}$ signals and an optical power of $-3 \mathrm{dBm}$ at the input of the photodetector. The RF signals were configured with $19 \mathrm{MHz}$ frequency offset, 64-QAM, and $20 \mathrm{MHz}$ bandwidth, thereby achieving a maximum throughput of $182.8 \mathrm{Mbit} / \mathrm{s}$ for the 5G NR and LTE-A signals. Figure $3 \mathrm{~b}$ reports the measured spectrum and detected constellations for the LTE-A and 5G NR signals. One can clearly distinguish each synchronism, control, and data symbols transmitted as the obtained $\mathrm{EVM}_{\mathrm{RMS}}$ were $2.5 \%$ and $2.4 \%$ for $5 \mathrm{G} \mathrm{NR}$ and LTE-A, respectively. Furthermore, there were no noticeable phase rotation distortions in the detected constellations after the fiber-wireless transmission, thus demonstrating successful and seamless coexistence between 5G NR and LTE-A signals.

\subsection{Combined Fiber-Optic and FSO-Based 5G Fronthaul}

The combined fiber-optic and FSO-based 5G fronthaul followed by wireless access extension is described in a block diagram in Figure 4a. The system encompasses RoF, FSO, and wireless technologies in a single architecture that takes advantage of a hybrid $\mathrm{RoF} / \mathrm{FSO}$ link for fronthaul integration followed by dual-band 5G NR wireless access. The FSO link enables last-mile applications when there are restrictions to the placement of a fiber-optic connection, thereby increasing system flexibility. After photodetection, further reach is achieved by wireless access.

For the experiments, we simultaneously transmitted two RF signals in the hybrid configuration in accordance with the frequency bands standardized by 3GPP Release 15 . A $100 \mathrm{MHz}$ bandwidth $5 \mathrm{G} \mathrm{NR}$ signal at $3.5 \mathrm{GHz}$ was generated using the $\mathrm{VSG}_{1}$, whereas a $400 \mathrm{MHz}$ bandwidth M-QAM signal was generated in baseband using an AWG and upconverted to $26 \mathrm{GHz}$ by means of the $\mathrm{VSG}_{2}$. Finally, a diplexer combined both signals, resulting in $3 \mathrm{dBm}$ electrical power at the optical modulator. An OS-TL-D-C-50-200-1S-FA DFB laser from Golight generated a $13 \mathrm{dBm}$ optical carrier at $1550 \mathrm{~nm}$, which was modulated by the RF-driven signals discussed above using a single-drive MZM. The modulated optical carrier was transmitted throughout a $12.5 \mathrm{~km}$ fiber-optic fronthaul to the collimator, and then, as a proof-of-concept, it followed a $1 \mathrm{~m}$ long FSO fronthaul in such a way as to assure an eye-safe FSO link. 


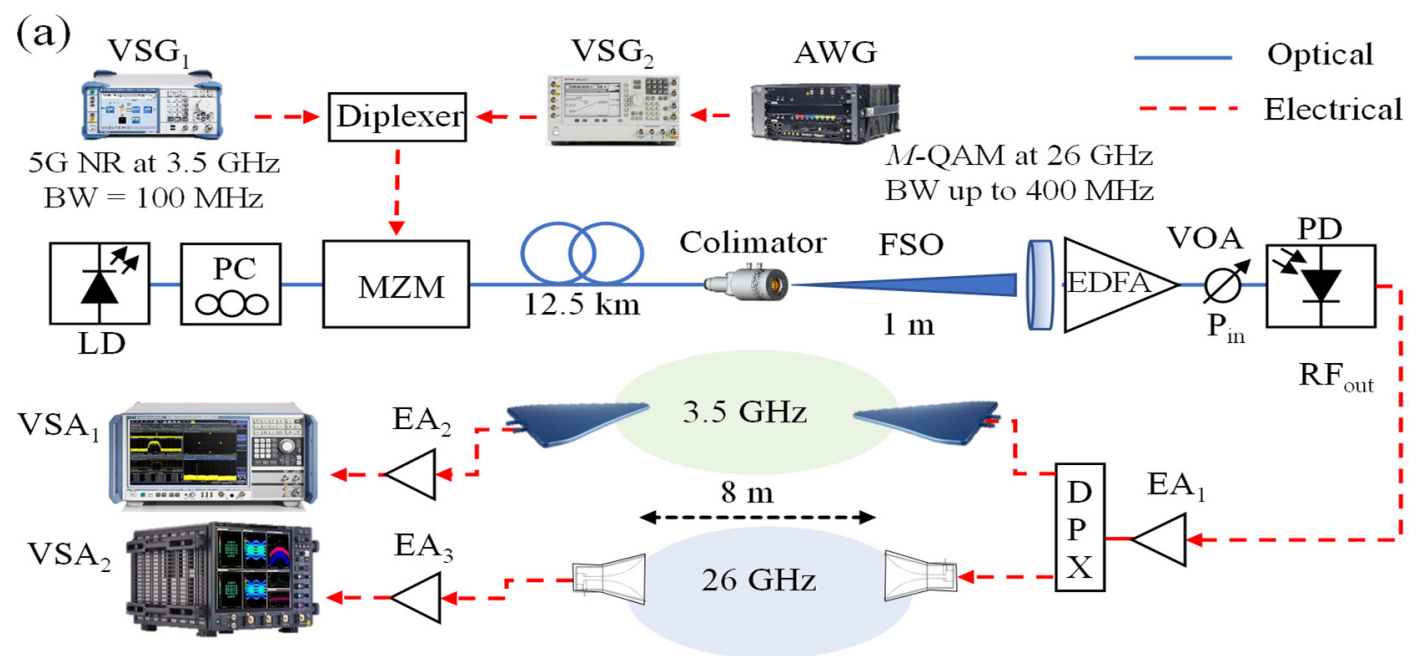

(b)

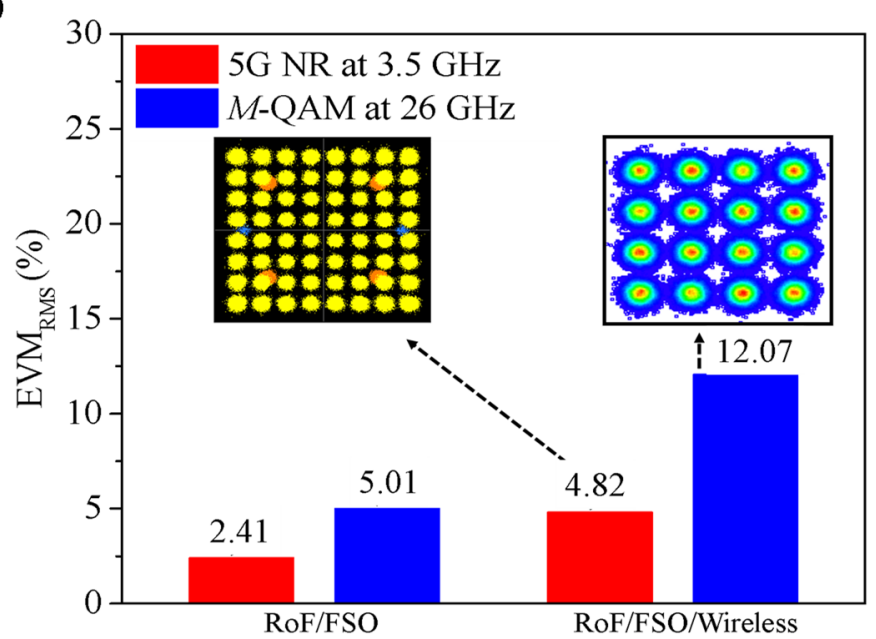

Figure 4. Combined fiber-optic and FSO-based 5G fronthaul architecture. (a) Block diagram; (b) performance analysis of 5G NR and M-QAM signals in the optical-wireless system. The constellations from the RoF/FSO/wireless approach show 16and 64-QAM received symbols suitable for demodulation.

At the receiver side, an optical lens with a 5-fold collimation factor coupled the free-space optical beam into an optical patch cord. A 3-axis micropositioner was used to minimize vibration and misalignments losses. Next, the optical signal was amplified by an EDFA, whereas a variable optical attenuator (VOA) and an optical power monitor (OPM) were used for controlling and monitoring the optical power at the input of the PIN broadband photodetector from $\mathrm{u}^{2} \mathrm{t}$. It is worth highlighting that the EDFA noise was considered in the approach as there was no filter before the photodetector. If the EDFA amplified spontaneous emission (ASE) had been filtered out, an enhanced performance could have been achieved. After photodetection, the resulting RF signals were amplified by the electrical amplifier $\mathrm{EA}_{1}$ by about $24 \mathrm{~dB}$. A diplexer was used to separate the 3.5 and $26 \mathrm{GHz}$ signals. Two $5 \mathrm{dBi}$ gain log-periodic antennas were used for transmitting and receiving the $5 \mathrm{G}$ NR signal at $3.5 \mathrm{GHz}$. In parallel, two $25 \mathrm{dBi}$ gain horn antennas enabled $8 \mathrm{~m}$ of $\mathrm{mm}$-wave wireless link at $26 \mathrm{GHz}$ aimed at indoor applications. At the receiver side, the 5G signal was amplified $\left(\mathrm{EA}_{2}\right)$ by $20 \mathrm{~dB}$ and evaluated employing an FSW-8351VSA $\left(\mathrm{VSA}_{1}\right)$. Meanwhile, the $400 \mathrm{MHz}$ bandwidth $M$-QAM signal was amplified $\left(\mathrm{EA}_{3}\right)$ by $35 \mathrm{~dB}$ and evaluated using a DSAZ632A high-frequency oscilloscope (VSA $\left.{ }_{2}\right)$.

The system performance was investigated by assessing the hybrid architecture in two distinct scenarios in terms of $\mathrm{EVM}_{\mathrm{RMS}}$ and in accordance with 3GPP Release 15 specifications. The first step was to evaluate the hybrid RoF/FSO fronthaul at the photodetector 
output, whereas the second step consisted of actually analyzing the dual-band 5G NR wireless system employing the hybrid RoF/FSO fronthaul, as depicted in Figure 4b. It is worth mentioning that the experimental results were achieved using $3 \mathrm{dBm}$ optical power at the photodetector input for both scenarios. In particular, for the 5G NR signal at $3.5 \mathrm{GHz}$, we selected 64-QAM, which resulted in $578 \mathrm{Mbit} / \mathrm{s}$ and measured $\mathrm{EVM}_{\mathrm{RMS}}$ of around $2.4 \%$, thereby satisfying the 3GPP requirements $(8 \%)$ by a wide margin. Likewise, the received $400 \mathrm{MHz}$ bandwidth signal at $26 \mathrm{GHz}$ was within the 3GPP recommendations, providing $2.4 \mathrm{Gbit} / \mathrm{s}$ throughput. The increased $\mathrm{EVM}_{\mathrm{RMS}}$ value (5\%) for mm-wave transmission was due to the RF cables, SD-MZM, and photodetector frequency responses at the mm-wave band. Overall, the proposed hybrid RoF/FSO fronthaul provided $3 \mathrm{Gbit} / \mathrm{s}$ of total throughput, which is within the $3 \mathrm{GPP}$ requirements for $\mathrm{EVM}_{\mathrm{RMS}}$, thereby enabling further network reach by wireless access.

The second analysis consisted of evaluating the combined fiber-optic and FSO-based $5 \mathrm{G}$ fronthaul followed by the $8 \mathrm{~m}$ wireless access, as reported in Figure $4 \mathrm{~b}$. As expected, the wireless channel impaired the transmitted signal in both phase and magnitude as could be observed by the received symbols in the RoF/FSO/wireless constellations. Nevertheless, the 5G NR signal attained the $\mathrm{EVM}_{\mathrm{RMS}}$ requirements with $3.2 \%$ margin, which may be explored for either increasing the signal data rate or extending the wireless reach. In contrast, the propagation conditions at $26 \mathrm{GHz}$ critically impaired the $400 \mathrm{MHz}$ bandwidth signal, and hence the $\mathrm{EVM}_{\mathrm{RMS}}$ did not meet the $3 \mathrm{GPP}$ recommendations. As an alternative, we employed a $200 \mathrm{MHz}$ bandwidth under 16-QAM to overcome this performance shortcoming. With this bandwidth reduction, the hybrid dual-band 5G NR system achieved an $E M_{R M S}$ value of around $12 \%$, which is still within the 3GPP limit for 16-QAM (12.5\%), due to the severe propagation impairments at mm-waves. In spite of the bandwidth reduction at $26 \mathrm{GHz}$, the hybrid RoF/FSO/wireless 5G NR system was able to provide $1.4 \mathrm{Gbit} / \mathrm{s}$ total throughput, thus fulfilling the Release 15 recommendations and demonstrating feasibility of the system while giving the remarkable additional advantage of FSO fronthaul flexibility.

\section{4G/5G NR VLC-Based Access Network}

VLC has emerged as an alternative for transmitting the 5G NR standard or other wireless signals in environments where electromagnetic interferences must be minimal, such as in hospitals, petrochemical industrial plants, and airplanes. Furthermore, LEDbased VLC systems can take advantage of environment lighting to provide free-space data transmission using wavelengths in the visible part of the optical spectrum. The LED is directly modulated, and the optical link operates in IM-DD mode at the photodiode [28]. By using an LED, the wide light beam divergence allows the desired area to be fully eliminated, thereby enabling simultaneous access for multiple devices and/or patterns of data traffic [21]. In addition, carrier aggregation strategies can be employed to increase the effective user throughput.

Figure 5a depicts the experimental set-up diagram of the LED-based VLC access point for simultaneous transmission of the 5G NR standard signal and an LTE-A three-band signal. RGBA (red, green, blue, and amber) LEDs were considered as the light source because they provide larger modulation bandwidth in comparison to white commercial LEDs [29]. In particular, the final selection of red LED (623 nm optical carrier) was dictated by the manufacturer's datasheet, which indicates that this wavelength offers the best trade-off between output power and quantum efficiency. In the experiments, the 5G NR signal was generated using a SMBV100B vector signal generator $\left(\mathrm{VSG}_{1}\right)$, while a PSGE8267D vector signal generator $\left(\mathrm{VSG}_{2}\right)$ and a M9505A arbitrary waveform generator (AWG) were employed to generate the LTE-A three-band signal. The RF signals were electrically combined and directly modulated the red LED by means of a bias tee. The LED light beam directivity was enhanced by a reflector and launched in a free-space link of $0.75 \mathrm{~m}$.

At the receiver side, a plane convex lens with the diameter and focal distance of 25.4 and $35.0 \mathrm{~mm}$, respectively, was used to focus the incident beam at the input of the PIN 
photodetector (EOT ET-2030). Next, an RLC equalizer similar to the one described in [29] was implemented to compensate for the LED frequency response. A DC blocker ensured that the DC component from the OE conversion did not reach the VSA. Finally, a cascade of four electrical amplifiers (EAs) assured a $50 \mathrm{~dB}$ gain in the received signal.

The system performance was evaluated by $\mathrm{EVM}_{\mathrm{RMS}}$ measurements. The $5 \mathrm{G}$ NR signal was generated with a bandwidth of $10 \mathrm{MHz}, 64-\mathrm{QAM}$, centered at $46 \mathrm{MHz}$. The configuration of the LTE-A signal represented the aggregation of three intra-band carriers in order to triplicate the effective throughput of a single user. Specifically, the LTE-A signal was generated with three sub-bands of $12 \mathrm{MHz}, 64-\mathrm{QAM}$, at 57,69 , and $81 \mathrm{MHz}$, named as 64- $\mathrm{QAM}_{1}, 64-\mathrm{QAM}_{2}$, and 64-QAM 3 , respectively.

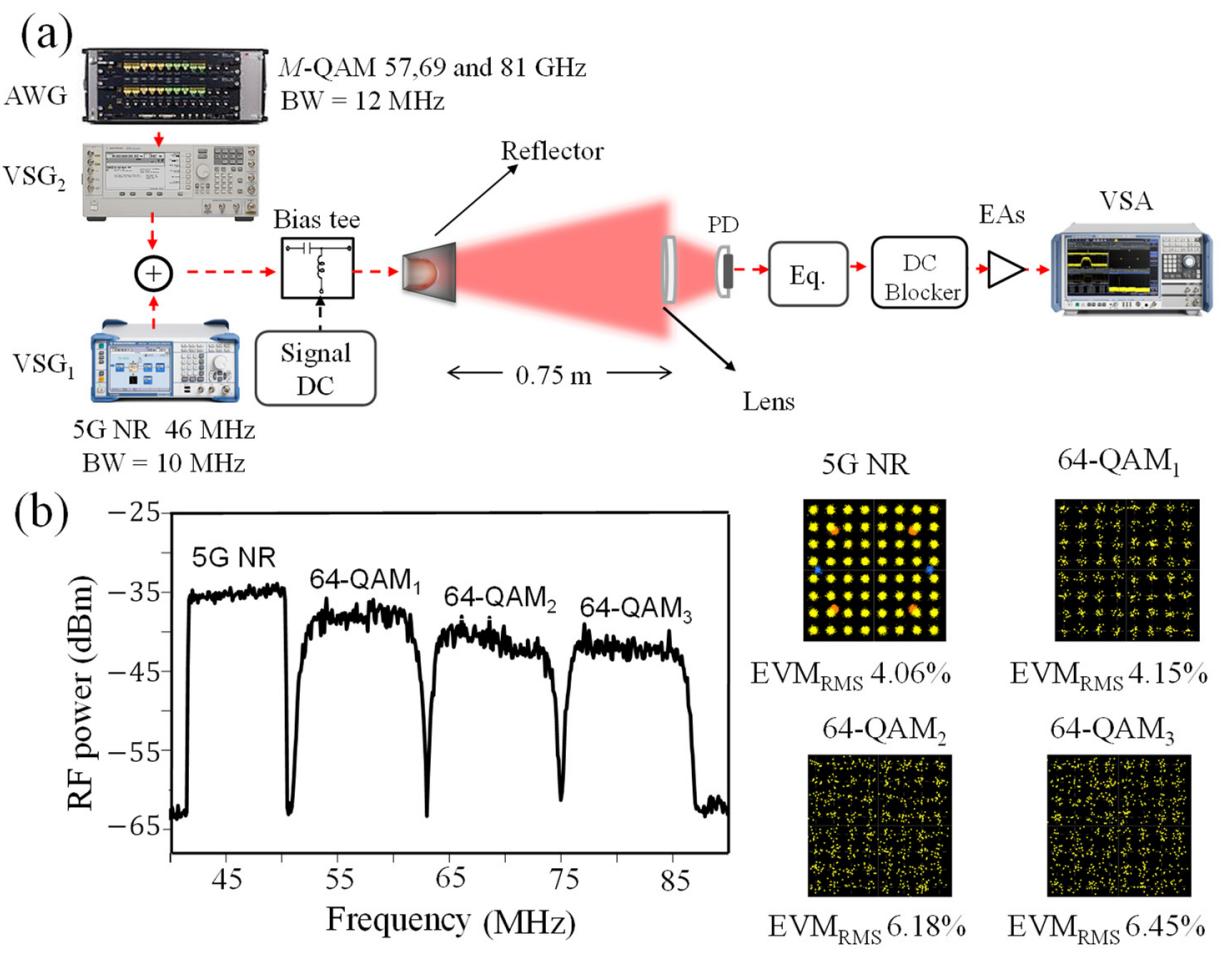

Figure 5. The 4G/5G NR VLC-based access network architecture. (a) Block diagram; (b) electrical spectrum and $\mathrm{EVM}_{\mathrm{RMS}}$ at the receiver.

Figure $5 \mathrm{~b}$ shows the received spectrum as well as the measured constellations and $\mathrm{EVM}_{\mathrm{RMS}}$ values. The received signal power decreased as the operation frequency increased on account of the LED frequency response, degrading both the signal-noise ratio (SNR) and the $\mathrm{EVM}_{\mathrm{RMS}}$ value. The constellations in Figure $5 \mathrm{~b}$ illustrate these performance issues by considering the four transmitted bands. The measured $\mathrm{EVM}_{\mathrm{RMS}}$ values were $4.06 \%, 4.15 \%$, $6.18 \%$, and $6.45 \%$ for $5 \mathrm{G} \mathrm{NR}, 64-\mathrm{QAM}_{1}, 64-\mathrm{QAM}_{2}$, and $64-\mathrm{QAM}_{3}$, respectively, which are all within the 3GPP limit of $8 \%$ for the 64-QAM format [27]. The effective throughputs measured for the 5G NR signal and the aggregation of the three 64-QAM signals were 38 and $180 \mathrm{Mbit} / \mathrm{s}$, respectively, rates which are attractive for a VLC access point.

\section{Related Works and Comparison to the State of the Art}

This section reports on a review of the state of the art by comparing optical-wireless techniques for 5G radio access network reported in the literature to the results of our implementation. Five architectures were considered, namely FiWi mm-wave/IFoF links, multiuser FiWi links, parallel FiWi and FSO relay links, RoF links followed by a FSO-section, and VLC access. Table 1 summarizes the aforementioned literature and comparisons to our work with the aim of contributing to and advancing the body of knowledge in this field. 
Table 1. State of the art on optical-wireless techniques for 5G radio access network.

\begin{tabular}{|c|c|c|c|c|c|c|}
\hline Reference & Architecture & Application & RF Bands & $\begin{array}{c}\text { Modulation/ } \\
\text { Waveform }\end{array}$ & Transmitter & Throughput \\
\hline [30] & $\begin{array}{c}\text { - FiWi mm-wave/ } \\
\text { IFoF link }\end{array}$ & $-\mathrm{RF}$ & $\begin{array}{l}-57 \mathrm{GHz} \\
-91 \mathrm{GHz}\end{array}$ & - OFDM & $\begin{array}{c}\text { - External cavity } \\
\text { laser + in-phase } \\
\text { and quadrature } \\
\text { (IQ)-MZM }\end{array}$ & $-24 \mathrm{Gbit} / \mathrm{s}$ \\
\hline [31] & $\begin{array}{c}\text { - FiWi mm-wave/ } \\
\text { IFoF link }\end{array}$ & $-5 G$ & - 57-64 GHz & $\begin{array}{c}\text { - QPSK } \\
\text {-16-QAM } \\
\end{array}$ & - LD + SD-MZM & - 24 Gbit/s \\
\hline [32] & $\begin{array}{c}\text { - FiWi mm-wave/ } \\
\text { IFoF link }\end{array}$ & $\begin{array}{l}-5 \mathrm{G} \\
- \text { FTTH }\end{array}$ & $-60 \mathrm{GHz}$ & - 16-QAM & - LD + SD-MZM & - Not specified \\
\hline [14] & - Multi-user FiWi links & $\begin{array}{l}\text { - } 5 \mathrm{G} \\
- \text { FTTH } \\
- \text { M2M }\end{array}$ & $\begin{array}{l}\text { - Baseband } \\
-700 \mathrm{MHz} \\
-3.5 \mathrm{GHz} \\
-26 \mathrm{GHz}\end{array}$ & $\begin{array}{c}\text { - OFDM, GFDM, } \\
\text { F-OFDM, M-QAM } \\
\text { and Standard 5G NR }\end{array}$ & - LD + DD-MZM & - $4.41 \mathrm{Gbit} / \mathrm{s}$ \\
\hline [33] & - Multi-user FiWi links & $-5 G$ & $-60 \mathrm{GHz}$ & - QPSK & - LD + SD-MZM & $-0.6 \mathrm{Gbit} / \mathrm{s}$ \\
\hline [34] & - Multi-user FiWi links & $-5 G$ & $-28 \mathrm{GHz}$ & - 16- and 64-QAM & $\begin{array}{l}\text { - RF combiner + } \\
\text { LD }\end{array}$ & -6 Gbit/s \\
\hline [35] & - Multi-user FiWi links & $-5 G$ & $\begin{array}{l}-17.6 \mathrm{GHz} \\
-26 \mathrm{GHz}\end{array}$ & - M-QAM & $\begin{array}{l}\text { - LD + SD-MZM + } \\
\text { optical ring } \\
\text { resonators }\end{array}$ & $-21 \mathrm{Gbit} / \mathrm{s}$ \\
\hline [36] & - mm-wave/FSO links & $\begin{array}{l}\text { - Backhaul } \\
\text { /fronthaul }\end{array}$ & $-60 \mathrm{GHz}$ & - BPSK & - Bias tee + LD & $-1 \mathrm{Gbit} / \mathrm{s}$ \\
\hline [37] & - mm-wave/FSO links & $-5 G$ & $-60 \mathrm{GHz}$ & $\begin{array}{l}\text { - 16-QAM } \\
\text { - OFDM }\end{array}$ & $\begin{array}{c}\text { - DFB laser + } \\
\text { MZM }\end{array}$ & - 4 Gbit/s \\
\hline [25] & - mm-wave/FSO links & $-5 G$ & $-28 \mathrm{GHz}$ & $\begin{array}{c}-16-Q A M \\
-5 G \\
\end{array}$ & - LD + MZM & - 1 Gbit/s \\
\hline [18] & - RoF/FSO/Wireless links & $-5 G$ & $-25 \mathrm{GHz}$ & - Standard LTE & - LD + 2-MZMs & $-120 \mathrm{Mbit} / \mathrm{s}$ \\
\hline [19] & - RoF/FSO/Wireless links & $-5 G$ & $\begin{array}{l}-2.12 \mathrm{GHz} \\
-2.6 \mathrm{GHz} \\
-3.5 \mathrm{GHz} \\
\end{array}$ & $\begin{array}{c}\text { - Standard LTE-A } \\
\text { - 5G NR }\end{array}$ & - SFP module & - Not specified \\
\hline [24] & - RoF/FSO/Wireless links & $\begin{array}{l}\text { - Fronthaul } \\
\text { - Access }\end{array}$ & $-24-26 \mathrm{GHz}$ & - 64-QAM & - Bias tee + LD & $-600 \mathrm{Mbit} / \mathrm{s}$ \\
\hline [38] & - VLC access & - Access point & - & - OOK & $\begin{array}{c}\text { - Bias tee }+ \\
\text { GaN-based LED }\end{array}$ & - $2.3 \mathrm{Gbit} / \mathrm{s}$ \\
\hline [39] & - VLC access & $-5 G$ & - & $\begin{array}{l}\text { - OFDM, GFDM } \\
\text { and FBMC }\end{array}$ & - Bias tee + LED & - $10 \mathrm{Mbit} / \mathrm{s}$ \\
\hline [40] & - VLC access & - Access point & - & - DCO-OFDM & $\begin{array}{c}\text { - Bias tee }+ \\
\text { phosphor LD }\end{array}$ & $-6.9 \mathrm{Gbit} / \mathrm{s}$ \\
\hline This work & $\begin{array}{c}\text { - FiWi multi-user } \\
\text { mm-Wave/RoF link } \\
\text { - Parallel FiWi and FSO } \\
\text { links } \\
\text { - RoF/FSO-based link } \\
\text { - VLC access }\end{array}$ & $\begin{array}{l}-4 G \\
-5 G\end{array}$ & $\begin{array}{l}-700 \mathrm{MHz} \\
-3.5 \mathrm{GHz} \\
-26 \mathrm{GHz} \\
-38 \mathrm{GHz}\end{array}$ & $\begin{array}{c}\text { - M-QAM } \\
\text { - LTE standard } \\
\text { - 5G NR standard }\end{array}$ & $\begin{array}{l}-\mathrm{LD}+\mathrm{SD}-\mathrm{MZM} \\
-\mathrm{LD}+\mathrm{DD}-\mathrm{MZM} \\
- \text { Bias tee + LED }\end{array}$ & $\begin{array}{c}-182.8 \mathrm{Mbit} / \mathrm{s} \\
-1.61 \mathrm{Gbit} / \mathrm{s} \\
-1.4 \mathrm{Gbit} / \mathrm{s} \\
-218 \mathrm{Mbit} / \mathrm{s}\end{array}$ \\
\hline
\end{tabular}

FiWi mm-wave/IFoF architectures, which include digital or analog RoF approaches followed by wireless transmission, have benefited from diverse technical solutions aimed at improving capacity and coverage [30-32]. For instance, Li et al. reported a $24 \mathrm{Gbit} / \mathrm{s}$ FiWi mm-wave link by exploiting $6 \mathrm{GHz}$ bandwidth [30], whereas Argyris et al. demonstrated a similar bit rate in a mm-wave/IFoF link with electrical subcarrier multiplexing [31]. Mm-wave/IFoF links have even been deployed over legacy PON as an alternative for 5G fronthauling [32].

Advances in the multiuser FiWi links include simultaneous transmission of multiple RF signals at distinct frequency bands [14] as well as the use of phased array antennas for beamforming and beamsteering [33-35]. In [14], we presented a FiWi system over legacy PON based on DD-MZM that was able to cover the 5G eMBB scenario at FR1 and FR2, thereby enabling applications including long reach, fiber-to-the-home, and machine-tomachine communication. In [33], Ruggeri et al. reported a multiuser FiWi mm-wave/IFoF system taking advantage of a 32-element $60 \mathrm{GHz}$ phased array antenna with beamsteering capability. In [34], Huang et al. demonstrated the possibility of integrating self-steering array beamforming to the FiWi architecture. Additionally, a photonic beamforming-based FiWi architecture was experimentally demonstrated in [35]. 
Multiple works have reported a hybrid mm-wave and FSO fronthaul aimed at increasing system reliability. The FSO and mm-waves links can operate in distinct architectures, namely simultaneous transmission for increased throughput in parallel with switchable transmission and a cascade system with FSO followed by a wireless link. Shakir et al. reported a hybrid system that simultaneously transmitted the same data over both links, namely an FSO at $1550 \mathrm{~nm}$ and mm-waves at $60 \mathrm{GHz}$ [36]. The link selection was based on SNR for both approaches in accordance with decision thresholds aimed at evaluating BPSK transmission in a turbulent channel. Zhang et al. presented a hybrid FSO and mm-wave link for $5 \mathrm{G}$ backhauls operating at $1553.96 \mathrm{~nm}$ and $60 \mathrm{GHz}$, respectively. The link option was based on maximum-ratio combining (MRC) and was evaluated in terms of EVM RMS for a 16-QAM signal in turbulent, fog, and rain conditions [37]. Additionally, the authors in [25] reported a hybrid $1550 \mathrm{~nm}$ FSO link cascaded with a $28 \mathrm{GHz}$ RF link for 5G backhaul and fronthaul applications. The experiments consisted of evaluating the cascaded approach in terms of bit error rate (BER), EVM, and visibility range under the same dusty conditions. The experimental results demonstrated that the dust environment did not impair the RF link at $28 \mathrm{GHz}$, enabling the RF link to operate as a backup for FSO [25].

The FSO link has also been employed for extending the RoF fronthaul to sites where fiber optics do not reach, thus maintaining the optical communication advantages. In this way, Mufutau et al. demonstrated a hybrid 4G/5G optical fiber-wireless system, including a free-space optics fronthaul [19]. The results showed that a $100 \mathrm{MHz}$ bandwidth 5G signal transmission using A-RoF throughout a $8 \mathrm{~km}$ fiber-optic fronthaul could coexist on the same LTE fronthaul infrastructure. Additionally, a hybrid fiber and FSO fronthaul demonstrated the $4 \mathrm{G}$ and $5 \mathrm{G}$ operability at 2.6 and $3.5 \mathrm{GHz}$, respectively. Nguyen et al. experimentally implemented a radio-over-fiber followed by an FSO fronthaul and mmwaves wireless transmission aimed at broadband wireless access [18]. The performance was evaluated by transmitting 4-, 16-, and 64-QAM LTE signals over the hybrid link and evaluating the EVM parameter as a function of weak-to-strong atmospheric turbulence regimes. Furthermore, Bohata et al. presented a radio-over-fiber combined with FSO and RF transmission for the 5G networks [24]. The authors used the 24-26 GHz frequency band and a particular direct intensity modulation solution for transmitting a $100 \mathrm{MHz}$ bandwidth 64-QAM signal. The link performance was evaluated by exposing the FSO section to atmospheric turbulence and analyzing the SNR and EVM RMS.

In parallel with the wireless techniques for access point, VLC systems have been emerging as a potential technology to accomplish the $5 \mathrm{G}$ requirements and beyond. They are mainly composed of light-emitting diodes, which can be used for simultaneously lighting the environment and transmitting data. In this way, Yeh et al. reported a GaN LED-based visible light communication using a $4 \times 4$ color polarization multiplexing and on-off keying (OOK) [38]. The system attained $2.3 \mathrm{Gbit} / \mathrm{s}$ over $1 \mathrm{~m}$ employing MIMO and pre-equalization under the illumination of 6.9-136.1 lux. Recent works have shown the use of VLC for 5G. For instance, Monteiro et al. reported a comparison among 5G waveform candidates, namely filter bank multicarrier (FBMC), generalized frequency division multiplexing (GFDM), and OFDM, with regard to a single-input single-output VLC system [39]. On the other hand, VLC systems may employ lasers as a light source to achieve higher throughput. Wei et al. reported a VLC system employing a white-light phosphor laser for illuminating and providing 6.9 Gbit/s over $1.5 \mathrm{~m} \mathrm{[40].}$

In this work, we examined an innovative proposal for optical-wireless architectures applied to the NSA 5G new radio framework. In contrast to previous works, we experimentally demonstrated $4 \mathrm{G}$ and $5 \mathrm{G}$ NR coexistence in the $700 \mathrm{MHz}$ band taking into account a FiWi system.

Regarding the dual wireless and FSO-based fronthaul architecture, our implementation employed the 5G NR standard. The parallel FSO at $1550 \mathrm{~nm}$ and mm-wave link at $38 \mathrm{GHz}$ enabled a dynamic selection according to its transmission performance, whereas the other link operated as a backup. Its performance was investigated by assessing the $\mathrm{EVM}_{\mathrm{RMS}}$ for different power levels at the receiver to emulate the equivalent attenuation 
levels for visibility and rain conditions. The attenuation levels used for the FSO link were from 0 to $56 \mathrm{~mm} / \mathrm{h}$, whereas the values ranged from 0 to $102 \mathrm{~mm} / \mathrm{h}$ for the wireless link. Overall, our 5G NR experimental results demonstrated $1.61 \mathrm{Gbit} / \mathrm{s}$ total throughput, which

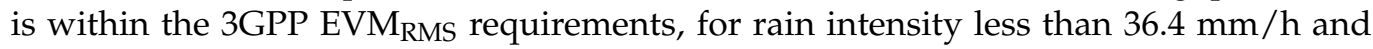
visibility above $40 \mathrm{~m}$.

Moreover, we examined a fiber-optic and FSO-based 5G fronthaul followed by a dual-band 5G NR wireless access, including mm-waves. The FSO link enables last-mile applications, thereby increasing system flexibility and providing optical fiber-like throughput. The system performance was investigated by assessing the hybrid architecture in two

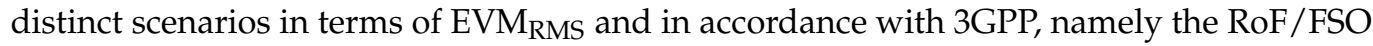
fronthaul at the photodetector output and the dual-band 5G NR wireless system employing RoF/FSO as fronthaul. Overall, the proposed hybrid RoF/FSO fronthaul provided 3 Gbit/s total throughput with plenty of margin in terms of $\mathrm{EVM}_{\mathrm{RMS}}$, thereby enabling wireless access. The dual-band 5G NR wireless system assisted by a hybrid RoF/FSO fronthaul demonstrated the feasibility of the system by providing $1.4 \mathrm{Gbit} / \mathrm{s}$ total throughput, thus fulfilling the 3GPP Release 15 specifications.

Finally, the RGB-based VLC system for indoor applications was examined, in which immunity to electromagnetic interference is crucial. We transmitted a standard 5G NR signal and 3 LTE-A bands in order to attend to multiple users employing a single red LED, which offers the best trade-off between output power and quantum efficiency. The system performance was evaluated by assessing each transmitted signal in terms of SNR,

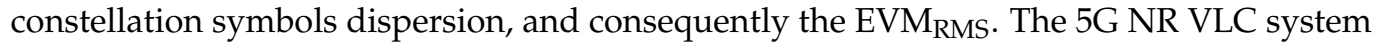
provided $218 \mathrm{Mbit} / \mathrm{s}$ throughput and $\mathrm{EVM}_{\mathrm{RMS}}$ as low as $6.45 \%$ considering all transmitted signals, thereby demonstrating the viability of VLC for $5 \mathrm{G}$ networks.

\section{Conclusions}

We have successfully proposed and reported on an efficient optical-wireless architecture applied to the non-standalone 5G new radio framework and compared the system to related works in the literature. Several distinct electrical- and optical-based fronthaul approaches combining free-space optical, wireless links, and RoF techniques were deployed for selection according to network operator requirements. First, a dual $38 \mathrm{GHz}$ wireless and FSO-based fronthaul architecture enabled a backup link for high-reliability services. Next, a fiber-wireless configuration based on an analog RoF link followed by a wireless extension was studied for simultaneous RF signal distribution of both LTE-A and 5G NR signals. Finally, fiber optics and FSO techniques were integrated into a single fronthaul to extend the fronthaul reach where fiber optics cannot be deployed. After photodetection, further access extension was achieved by wireless signal transmission of the two 3GPP Release 15 spectral bands of 3.5 and $26 \mathrm{GHz}$. All three investigated approaches demonstrated performance within the $3 \mathrm{GPP}$ EVM $\mathrm{RMS}_{\mathrm{S}}$ requirements prescribed by $5 \mathrm{G}$ NR Release 15 . In addition, a VLC access network with carrier aggregation was examined to increase user throughput when immunity to EM interference is paramount. The reported solutions may be integrated in a flexible optical-wireless platform for 5G and beyond, allowing their coexistence with $4 \mathrm{G}$ over a shared fronthaul infrastructure. Future works should consider implementation of the proposed architecture to either downlink an uplink or to increase the FSO reach up to hundreds of meters in an outdoor scenario.

Author Contributions: Conceptualization, A.C.S.J.; methodology, R.M.B.; validation, D.H.S. and M.A.R.; formal analysis, R.M.B., D.H.S., M.A.R. and A.C.S.J.; investigation, C.H.d.S.L., E.S.L., M.A.d.O., M.S.B.C., L.C.A., L.G.d.S. and L.A.M.P.; resources, A.C.S.J.; writing-original draft preparation, R.M.B., C.H.d.S.L., E.S.L., M.A.d.O., M.S.B.C., L.C.A., L.G.d.S. and L.A.M.P.; writing-review and editing, R.M.B. and M.A.R.; visualization, R.M.B.; supervision, D.H.S., M.A.R. and A.C.S.J.; project administration, A.C.S.J.; funding acquisition, M.A.R. and A.C.S.J. All authors have read and agreed to the published version of the manuscript. 
Funding: This work was partially supported by RNP with resources from MCTIC, Grant No. 01245.010604/2020-14, under the 6G Mobile Communications Systems project of the Radiocommunication Reference Center (Centro de Referência em Radiocomunicações-CRR) of the National Institute of Telecommunications (Instituto Nacional de Telecomunicações-Inatel), Brazil. The authors would also like to thank CNPq, CAPES, FINEP, and FAPEMIG for the financial support.

Institutional Review Board Statement: Not applicable.

Informed Consent Statement: Not applicable.

Data Availability Statement: Not applicable.

Conflicts of Interest: The authors declare no conflict of interest.

\section{References}

1. Parkvall, S.; Dahlman, E.; Furuskär, A.; Frenne, M. NR: The new 5G radio access technology. IEEE Commun. Stand. Mag. 2017, 1, 24-30. [CrossRef]

2. 5GPP. View on 5G architecture. White Paper. 2017. Available online: https://5g-ppp.eu/wp-content/uploads/2018/01/5G-PPP5G-Architecture-White-Paper-Jan-2018-v2.0.pdf (accessed on 26 May 2021).

3. 3GPP. 5G.; NR.; Overall description; Stage-2. TS 38.300 version 15.8.0 Release 15. 2020. Available online: https:/ / www.etsi.org/ deliver/etsi_ts/138300_138399/138300/15.08.00_60/ts_138300v150800p.pdf (accessed on 26 May 2021).

4. Tzanakaki, A.; Anastasopoulos, M.; Berberana, I.; Syrivelis, D.; Flegkas, P.; Korakis, T.; Mur, D.C.; Demirkol, I.; Gutierrez, J.; Grass, E.; et al. Wireless-optical network convergence: Enabling the 5G architecture to support operational and end-user services. IEEE Commun. Mag. 2017, 55, 184-192. [CrossRef]

5. Zhang, N.; Cheng, N.; Gamage, A.P.K.T.; Zhang, K.; Mark, J.W.; Shen, X. Cloud assisted HetNets toward 5G wireless networks. IEEE Commun. Mag. 2015, 53, 59-65. [CrossRef]

6. I, C.-L.; Li, H.; Korhonen, J.; Huang, J.; Han, L. RAN revolution with NGFI (xhaul) for 5G. J. Lightw. Technol. 2018, 36, 541-550. [CrossRef]

7. 3GPP. Release 16 description; Summary of Rel-16 work items. TR 21.916 v0.5.0. 2020. Available online: https://www.3gpp.org/ release-16 (accessed on 26 May 2021).

8. 3GPP. Release17. Available online: 3gpp.org/release-17 (accessed on 26 May 2021).

9. Dang, S.; Amin, O.; Shihada, B.; Alouini, M. What should 6G be? Nat. Electron. 2020, 3, 20-29. [CrossRef]

10. Zhang, Z.; Xiao, Y.; Ma, Z.; Xiao, M.; Ding, Z.; Lei, X.; Karagiannidis, G.K.; Fan, P. 6G wireless networks: Vision, requirements, architecture and key technologies. IEEE Veh. Technol. Mag. 2019, 14, 28-41. [CrossRef]

11. Kalfas, G.; Vagionas, C.; Antonopoulos, A.; Kartsakli, E.; Mesodiakaki, A.; Papaioannou, S.; Maniotis, P.; Vardakas, J.S.; Verikoukis, C.; Pleros, N. Next generation fiber-wireless fronthaul for 5G mmWave networks. IEEE Commun. Mag. 2019, 57, 138-144. [CrossRef]

12. Liu, C.; Wang, J.; Cheng, L.; Zhu, M.; Chang, G.-K. Key microwave-photonics technologies for next generation cloud-based radio access networks. J. Lightw. Technol. 2014, 32, 3452-3460. [CrossRef]

13. Yao, S.; Chen, Y.-W.; Su, S.-J.; Alfadhli, Y.; Shen, S.; Zhang, R.; Zhou, Q.; Chang, G.-K. Non-orthogonal uplink services through co-transport of D-RoF/A-RoF in mobile fronthaul. J. Lightw. Technol. 2020, 38, 3637-3643. [CrossRef]

14. Borges, R.M.; Pereira, L.A.M.; Filgueiras, H.R.D.; Ferreira, A.C.; Cunha, M.S.B.; Neto, E.R.; Spadoti, D.H.; Mendes, L.L.; Sodré Jr., A.C. DSP-based flexible-waveform and multi-application 5G fiber-wireless system. J. Lightw. Technol. 2020, 38, 642-653. [CrossRef]

15. Borges, R.M.; Lima, E.S.; Ferreira, A.C.; Spadoti, D.H.; Abreu, M.; Mendes, L.L.; Sodré Jr., A.C.; Junior, A.C.S. Multiband 5G NR system with photonic-assisted RF amplification. Opt. Lett. 2020, 45, 1539-1542. [CrossRef]

16. Lima, E.S.; Borges, R.M.; Pereira, L.A.M.; Filgueiras, H.R.D.; Alberti, A.M.; Sodré Jr., A.C. Multiband and photonically amplified fiber-wireless Xhaul. IEEE Access 2020, 8, 44381-44390. [CrossRef]

17. Filgueiras, H.R.D.; Borges, R.M.; Melo, M.C.; Brandao, T.H.; Sodré Jr., A.C. Dual-band wireless fronthaul using a FSS-based focal-point/Cassegrain antenna assisted by an optical midhaul. IEEE Access 2019, 7, 112578-112587. [CrossRef]

18. Nguyen, D.-N.; Bohata, J.; Komanec, M.; Zvanovec, S.; Ortega, B.; Ghassemlooy, Z. Seamless 25 GHz transmission of LTE 4/16/64-QAM signals over hybrid SMF/FSO and wireless link. J. Lightw. Technol. 2019, 37, 6040-6047. [CrossRef]

19. Mufutau, A.O.; Guiomar, F.P.; Fernandes, M.A.; Lorences-Riesgo, A.; Oliveira, A.; Monteiro, P.P. Demonstration of a hybrid optical fiber-wireless 5G fronthaul coexisting with end-to-end $4 \mathrm{G}$ networks. J. Opt. Commun. Netw. 2020, 12, 72-78. [CrossRef]

20. Koonen, T. Indoor optical wireless systems: Technology, trends, and applications. J. Lightw. Technol. 2018, 36, 1459-1467. [CrossRef]

21. Feng, L.; Hu, R.Q.; Wang, J.; Xu, P.; Qian, Y. Applying VLC in 5G networks: Architectures and key technologies. IEEE Netw. 2016, 30, 77-83. [CrossRef]

22. Ranaweera, C.; Wong, E.; Nirmalathas, A.; Jayasundara, C.; Lim, C. 5G C-RAN With Optical Fronthaul: An Analysis From a Deployment Perspective. J. Lightw. Technol. 2018, 36, 2059-2068. [CrossRef] 
23. ACG Research. An Economic Comparison of Fronthaul Architectures for 5G Networks. Available online: https://www.acgcc.com (accessed on 17 August 2020).

24. Bohata, J.; Komanec, M.; Spácil, J.; Ghassemlooy, Z.; Zvánovec, S.; Slavık, R. 24-26 GHz radio-over-fiber and free-space optics for fifth- generation systems. Opt. Lett. 2018, 43, 1035-1038. [CrossRef] [PubMed]

25. Esmail, M.A.; Ragheb, A.M.; Fathallah, H.A.; Altamimi, M.; Alshebeili, S.A. 5G-28 GHz signal transmission over hybrid all-optical FSO/RF link in dusty weather conditions. IEEE Access 2019, 7, 24404-24410. [CrossRef]

26. Agrawal, G.P. Applications of Nonlinear Fiber Optics, 1st ed.; Academic Press: Cambridge, MA, USA, 2001.

27. 3GPP. Group radio access network; NR.; User equipment (UE) radio transmission and reception; Part 1: Range 1 Standalone. TS 38.101-1 version 15.5.0 Release 15. 2019. Available online: https:/ / www.etsi.org/deliver/etsi_ts/138100_138199/13810101/15.05.00_60/ts_ 13810101v150500p.pdf (accessed on 17 August 2020).

28. Haas, H.; Yin, L.; Wang, Y.; Chen, C. What is lifi? J. Lightw. Technol. 2016, 34, 1533-1544. [CrossRef]

29. Huang, X.; Shi, J.; Li, J.; Wang, Y.; Wang, Y.; Chi, N. 750Mbit/s visible light communications employing 64QAM-OFDM based on amplitude equalization circuit. In Proceedings of the Optical Fiber Communication Conference, Los Angeles, CA, USA, 22-26 March 2015.

30. Li, X.; Xiao, X.; Xu, Y.; Wang, K.; Zhao, L.; Xiao, J.; Yu, J. Real-time demonstration of over 20 Gbit/s V- and W-band wireless transmission capacity in one OFDM-RoF system. In Proceedings of the Optical Fiber Communications Conference (OFC), Los Angeles, CA, USA, 19-23 March 2017.

31. Argyris, N.; Giannoulis, G.; Kanta, K.; Iliadis, N.; Vagionas, C.; Papaioannou, S.; Kalfas, G.; Apostolopoulos, D.; Caillaud, C.; Debrégeas, H.; et al. A $5 \mathrm{G} \mathrm{mmWave} \mathrm{fiber-wireless} \mathrm{IFoF} \mathrm{analog} \mathrm{mobile} \mathrm{fronthaul} \mathrm{link} \mathrm{with} \mathrm{up} \mathrm{to} 24 \mathrm{~Gb} / \mathrm{s}$ multi-band wireless capacity. J. Lightw. Technol. 2019, 37, 2883-2891. [CrossRef]

32. Kanta, K.; Pagano, A.; Ruggeri, E.; Agus, M.; Stratakos, I.; Mercinelli, R.; Vagionas, C.; Toumasis, P.; Kalfas, G.; Giannoulis, G.; et al. Analog fiber-wireless downlink transmission of IFoF/mmWave over in-field deployed legacy PON infrastructure for 5G fronthauling. J. Opt. Commun. Netw. 2020, 12, D57-D65. [CrossRef]

33. Ruggeri, E.; Tsakyridis, A.; Vagionas, C.; Leiba, Y.; Kalfas, G.; Pleros, N.; Miliou, A. Multi-user V-band uplink using a massive MIMO antenna and a fiber-wireless IFoF fronthaul for 5G mmWave small-cells. J. Lightw. Technol. 2020, 38, 5368-5374. [CrossRef]

34. Huang, M.-Y.; Chen, Y.-W.; Peng, P.-C.; Wang, H.; Chang, G.-K. A full field-of-view self-steering beamformer for 5G mm-wave fiber-wireless mobile fronthaul. J. Lightw. Technol. 2020, 38, 1221-1229. [CrossRef]

35. Morant, M.; Trinidad, A.; Tangdiongga, E.; Koonen, T.; Llorente, R. Experimental demonstration of mm-Wave 5G NR photonic beamforming based on ORRs and multicore fiber. IEEE Trans. Microw. Theory Techn. 2019, 67, 2928-2935. [CrossRef]

36. Shakir, W.M.R. Performance evaluation of a selection combining scheme for the hybrid FSO/RF system. IEEE Photon. J. 2017, 10, 1-10. [CrossRef]

37. Zhang, J.; Wang, J.; Xu, Y.; Xu, M.; Lu, F.; Cheng, L.; Yu, J.; Chang, G.-K. Fiber-wireless integrated mobile backhaul network based on a hybrid millimeter-wave and free-space-optics architecture with an adaptive diversity combining technique. Opt. Lett. 2016, 41, 1909-1912. [CrossRef]

38. Yeh, C.-H.; Weng, J.-H.; Chow, C.-W.; Luo, C.-M.; Xie, Y.-R.; Chen, C.-J.; Wu, M.-C. 1.7 to 2.3 Gbps OOK LED VLC transmission based on $4 \times 4$ color-polarization-multiplexing at extremely low illumination. IEEE Photon. J. 2019, 11, 1-6. [CrossRef]

39. Monteiro, F.T.; Costa, W.S.; Neves, J.L.C.; Silva, D.M.I.; Rocha, H.R.O.; Salles, E.O.T.; Silva, J.A.L. Experimental evaluation of pulse shaping based 5G multicarrier modulation formats in visible light communication systems. Opt. Commun. 2020, 457. [CrossRef]

40. Wei, L.-Y.; Liu, Y.; Chow, C.-W.; Chen, G.-H.; Peng, C.-W.; Guo, P.-C.; Tsai, J.-F.; Yeh, C.-H. 6.915-Gbit/s white-light phosphor laser diode-based DCO-OFDM visible light communication (VLC) system with functional transmission distance. Electron. Lett. 2020, 56, 945-947. [CrossRef] 